\title{
Immunoglobulin G4-related spinal pachymeningitis
}

Mousa N. Alrashdi, MBBS.MD

\begin{abstract}

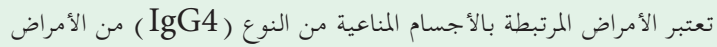

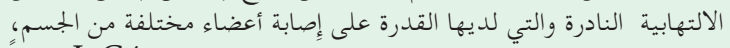

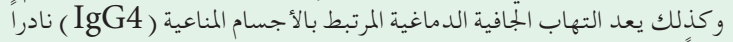

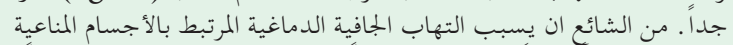

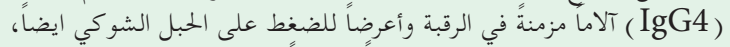

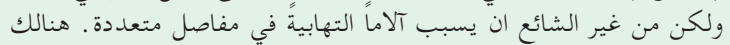

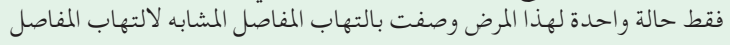

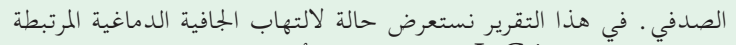

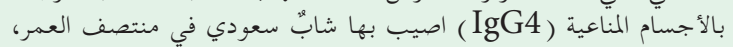

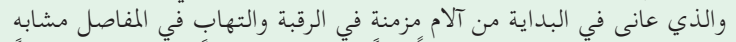

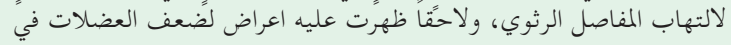

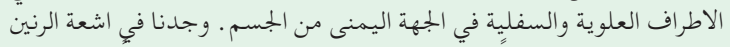

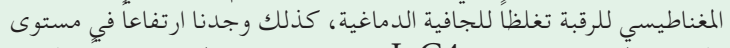

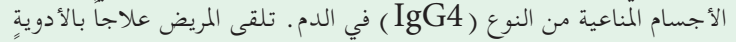

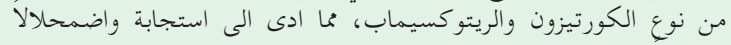
ملحوظا للجافية الدماغية في اشعة الرنين المغناطيسي المعادة للرقبة المبابة واضئ
\end{abstract}

Immunoglobulin G4-related disease (IgG4-RD) is rare disease entity and has recently been recognized as an inflammatory disorder with the tendency to affect multiple organs. Pachymeningitis of spine caused by IgG4-related disease is extremely rare. Neck pain and spinal cord compression symptoms consist of usual presentation of IgG4-related spinal pachymeningitis; however, polyarthritis is an unusual presentation of this disease, and it was reported in only one case that mimicked psoriatic arthritis. In this report, we describe a case of IgG4-related spinal pachymeningitis in a middle-age male who presented initially with neck pain and rheumatoid arthritis-like symptoms and later on developed both right upper and lower limb weakness. He was found to had pachymeningeal thickening on a cervical magnetic resonance image (MRI) and elevated serum IgG4 levels. He was treated with glucocorticoids and rituximab, which led to a significantly positive radiological response.

Keywords: immunoglobulin G4, IgG4-related spinal pachymeningitis, epidural mass

Saudi Med J 2020; Vol. 41 (6): 652-656 doi: 10.15537/smj.2020.6.25086
From the Department of Medicine, Collage of Medicine, Qassim University, Al Qassim, Kingdom of Saudi Arabia.

Received 7th November 2019. Accepted 21st April 2020.

Address correspondence and reprint request to: Dr. Mousa N. Alrashdi, Department of Medicine, Collage of Medicine, Qassim University, AlQassim, Kingdom ofSaudiArabia.E-mail:mosa4444@hotmail.com ORCID ID: https://orcid.org/0000-0001-6872-5161

Tmmunoglobulin G4-related (IgG4-RD) disease is an inflammatory and chronically immune-mediated fibrotic disease that consists of a variety of clinical presentations and different organ involvement, which causes it to mimic many other diseases, especially malignancy, infectious diseases, and other inflammatory disorders. ${ }^{1}$ The most commonly involved organs are the pancreas, salivary and lacrimal glands, and retroperitoneal area. Neurological involvement is relatively rare, and specifically, IgG4-related spinal pachymeningitis is extremely rare, and only 9 cases have been described in the literature. ${ }^{2,3}$ Diagnosis of an IgG4-related disease is challenging and based mainly on the presence of classical histopathological findings that consist of lympho-plasmocytic cell invasion, associated with heterogenic distribution of storiform fibrosis and obliterative phlebitis in examined tissue, which is usually difficult to be obtain. ${ }^{4}$ Magnetic resonance imaging findings in IgG4-related disease spinal involvement in the previous reported cases mostly affects cervical and thoracic vertebrae with sparing of intracranial area. ${ }^{3}$ In Saudi Arabia, no central nervous system involvement in IgG4-related diseases has previously been reported so far. In this report, we describe an adult Saudi male with late presentation of probable IgG4-related spinal pachymeningitis who initially presented with chronic neck pain and thickened epidural mass as observed on his cervical MRI. This finding stresses the importance of early recognition and treatment of this disease entity. Informed consent was obtained from the patient.

Case Report. A 36-year-old Saudi male was admitted to the Rheumatology Department, Security 
Forces Hospital, Riyadh, Saudi Arabia with a 4-month history of neck pain and progressive right arm and right leg weakness followed by a 1-month history of numbness over his right shoulder. Ten years earlier, he complained of chronic neck pain and was eventually found to have elongated cervical epidural thickening on a contrast cervical MRI. He was admitted under the neurosurgery team and underwent laminectomy and excision of the thickened epidural area. The pathology report concerning the removed tissues showed significant inflammatory plasma-lymphocytic cell infiltrations with scattered areas of fibrosis without granuloma; unfortunately, the sample was not examined by immunostaining for the possibility of IgG4-related disease (the slide was discarded). A cerebral spinal fluid (CSF) examination showed white blood cells of 20 with mainly neutrophils (70\%) with a CSF protein level of $0.51 \mathrm{~g} / \mathrm{L}$, normal glucose level, and Gram staining and cultures were negative. He was labeled as idiopathic pachymeningitis and discharged on daily dexamethasone of $2 \mathrm{mg}$ orally for 2 weeks.

Three years later, he was referred to the rheumatology clinic due to neck pain and non-erosive symmetrical polyarthritis involving his wrists and metacarpophalangeal (MCP) joints with both negative rheumatoid factor and anti-citrullinated protein antibodies. He was diagnosed as seronegative rheumatoid arthritis and started on $15 \mathrm{mg}$ of weekly oral methotrexate and $1 \mathrm{mg}$ of folic acid daily. At the follow-up, the patient reported that the arthritis and neck pain improved within the last 3 months and completely disappeared after 6 months. Due to fertility issues, he stopped methotrexate 2 years prior to his current presentation (Table 1). He had no family history of similar illness or other autoimmune rheumatic diseases.

Clinical information. Physical examination upon the most recent admission revealed muscle weakness in the right upper and lower limb (grade 3 in upper limb and +3 in lower limb and brisk re exes. Ho mann's sign in the right upper limb and Babinski sign in the right lower limb were noted. e rest of the clinical examination was unremarkable (Table 1).

Diagnostic assessment. Laboratory investigations revealed normal $\mathrm{CBC}$, renal and liver functions, erythrocyte sedimentation rate (ESR), and C-reactive

Disclosure. Authors have no conflict of interests, and the work was not supported or funded by any drug company. protein (CRP). An autoimmune work-up, including antinuclear antibody, anti-Sjogren's syndrome-related antigens $A$ and B (anti SSA and SSB, respectively) rheumatoid factor, and anti-citrullinated protein antibodies were negative. Immunoglobulin level showed marked elevation of $\operatorname{IgG}(19.2 \mathrm{~g} / \mathrm{L}$; reference value $7.0-16.0 \mathrm{~g} / \mathrm{L})$. The serum IgG4 level was $233 \mathrm{mg} / \mathrm{dl}$ (reference value 2.4-121 $\mathrm{mg} / \mathrm{dL}$ ). Cerebrospinal fluid analysis showed a white blood cell count of $380 / \mu \mathrm{L}$ consisting of predominantly lymphocytic, protein was $1 \mathrm{~g} / \mathrm{L}$, and glucose was $2.5 \mathrm{mmol} / \mathrm{L}$. Cerebrospinal fluid Gram staining, bacterial, mycobacterium tuberculosis, and fungal cultures were negative.

Cervical MRI prior to initiate treatment (Figure 1) demonstrates irregular pachy-meningeal thickening extending from the dorsal aspect of clivus to the T1 level with cord compression (Table 1).

Therapeutic intervention. Based on previously given data, the patient was diagnosed with probable IgG4related spinal pachymeningitis and treated accordingly. Intravenous dexamethasone $(20 \mathrm{mg})$ was administered for 3 consecutive days after which he received 2 doses of $1 \mathrm{~g}$ intravenous rituximab 2 weeks apart followed by $15 \mathrm{mg}$ of weekly oral methotrexate accompanied by daily folic acid $(1 \mathrm{mg})$ in addition to oral prednisone consisting of a daily dose of $1 \mathrm{mg} / \mathrm{kg}$ (Table 1 ).

Follow-up and outcome. His right shoulder numbness significantly improved within 2 days after dexamethasone therapy and completely resolved by one week; however, at the 4-months follow-up clinical examination, his right upper and lower limb weakness showed (graded +3 in upper limb and 4 in lower limb according to the manual muscle test proposed by Robert Lovett). A 4-month post-treatment follow-up; serum IgG4 level was $52 \mathrm{mg} / \mathrm{dl}$ (reference value $2.4-121 \mathrm{mg} / \mathrm{dL}$ ) and a repeated MRI (Figure 2) demonstrated significant improvement in enhanced lesions; however, the nonenhanced component remained unchanged (Table 1).

Discussion. Immunoglobulin G4-related disease has broad entity of clinical presentation that classically indolent in presentation and diagnosed late in disease course. ${ }^{5}$ This case was recognized as a spinal cord compressive epidural mass, and the patient underwent decompression spinal surgery after 2 years from his initial complaint in outpatient clinic attendance. Also, the IgG4-related disease rarely manifested as polyarthritis, which mimicked psoriatic arthritis as reported in one case only, ${ }^{6}$ but also can mimics rheumatoid arthritis as in our case, which has not been previously reported. 
Table 1 - Timeline flowchart.

\begin{tabular}{|c|c|c|c|}
\hline Dates & Clinical presentation & Diagnostic findings & Intervention and outcome \\
\hline July 2008 & $\begin{array}{l}\text { Present with chronic neck pain diagnosed with } \\
\text { idiopathic pachymeningitis }\end{array}$ & $\begin{array}{l}\text { Thickened epidura showed significant } \\
\text { inflammatory plasma-lymphocytic } \\
\text { cell infiltrations with scattered areas of } \\
\text { fibrosis }\end{array}$ & $\begin{array}{l}\text { Underwent laminectomy and excision of } \\
\text { the thickened epidura }\end{array}$ \\
\hline $\begin{array}{l}\text { October } \\
2011\end{array}$ & $\begin{array}{l}\text { Present with neck pain and non-erosive } \\
\text { symmetrical polyarthritis involving his wrists } \\
\text { and metacarpophalangeal joints, labeled as } \\
\text { seronegative rheumatoid arthritis }\end{array}$ & $\begin{array}{l}\text { Negative rheumatoid factor and anti- } \\
\text { citrullinated protein antibodies }\end{array}$ & $\begin{array}{l}\text { Started on } 15 \mathrm{mg} \text { of weekly oral } \\
\text { methotrexate and } 1 \mathrm{mg} \text { of folic acid daily }\end{array}$ \\
\hline $\begin{array}{l}\text { January } \\
2016\end{array}$ & & & $\begin{array}{l}\text { Due to fertility issues, he stopped } \\
\text { methotrexate }\end{array}$ \\
\hline $\begin{array}{l}\text { February } \\
2018\end{array}$ & $\begin{array}{l}\text { Present with 4-months of neck pain and right } \\
\text { side weakness and numbness. }\end{array}$ & $\begin{array}{l}\text { Irregular pachy-meningeal thickening } \\
\text { on cervical MRI and elevated serum } \\
\text { immunoglobulin G4-related disease } \\
\text { (IgG4-RD) level }\end{array}$ & $\begin{array}{l}\text { Intravenous(IV) dexamethasone }(20 \\
\mathrm{mg}) \text { for three days followed by } 1 \mathrm{mg} / \\
\mathrm{kg} \text { oral prednisone. Two doses of } 1 \mathrm{~g} \text { IV } \\
\text { rituximab two weeks apart. } 15 \mathrm{mg} \text { of } \\
\text { weekly oral methotrexate accompanied } \\
\text { by daily folic acid ( } 1 \mathrm{mg}) .\end{array}$ \\
\hline June 2018 & $\begin{array}{l}\text { Improved neck pain, numbness and right side } \\
\text { weakness }\end{array}$ & $\begin{array}{l}\text { MRI demonstrated significant } \\
\text { improvement in enhanced lesions. } \\
\text { Normal serum IgG4 level }\end{array}$ & \\
\hline
\end{tabular}

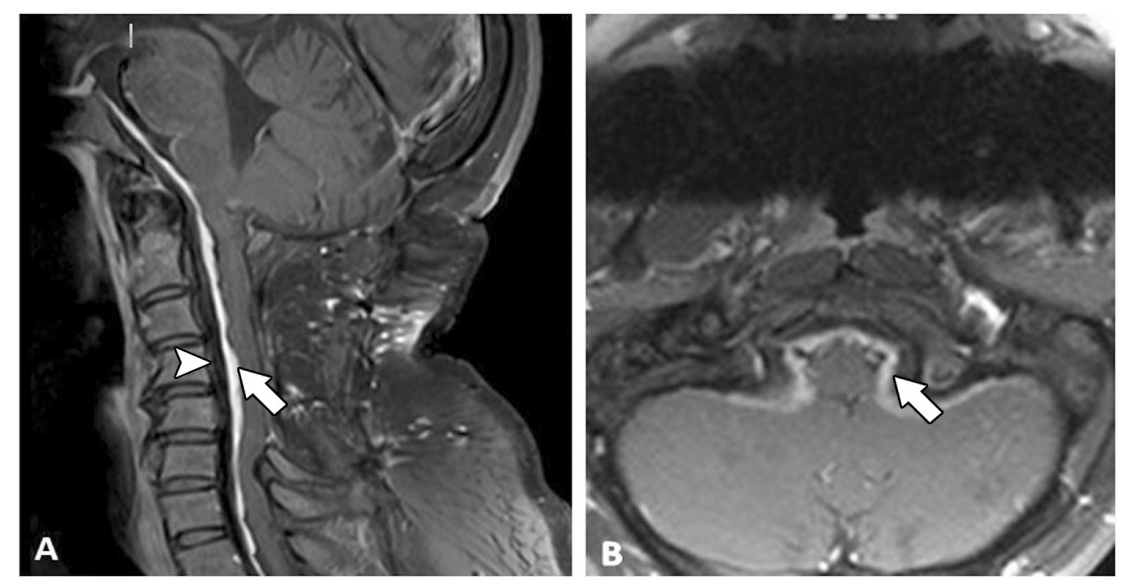

Figure 1 - A) Sagital and B) axial T1-Fat Sat postcontrast MR showing thickening extending from the dorsal aspect of clivus to $\mathrm{T} 1$ level with cord compression (arrow). The non-enhancing and low signal anterior to the enhancing component is consistent with chronic fibrotic changes (arrow head).

Rarity of IgG4-related spinal pachymeningitis and RA like presentation lead to significant delay in recognition and proper treatment in this patient.

Magnetic resonance imaging findings in IgG4related disease spinal involvement in the previous reported cases mostly affects cervical and thoracic vertebrae with sparing of intracranial area. ${ }^{3}$ Our case had cervical involvement extending from the dorsal aspect of clivus to the T1 level, which correlated with the aggressiveness of disease presentation and clinical examination.
The International Consensus Guidance statements on the Management and Treatment of IgG4-related disease recommend a biopsy of affected tissue in order to diagnose IgG4-related disease and to exclude malignancy and other mimicking diseases. ${ }^{7}$ We believe that retrospective chart review of our patient for his epidural biopsy microscopic description which was carried out in 2007 by pathologist match and fit the classical pathological findings of IgG4-related disease with exception of lack of doing immune-staining for 

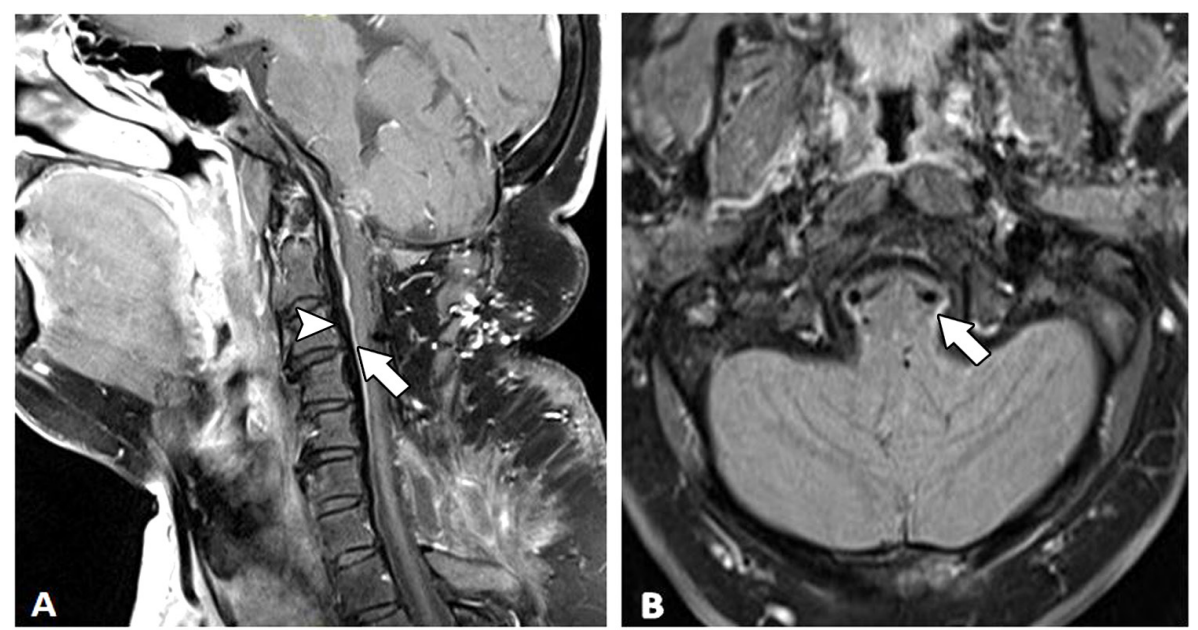

Figure 2 - A) Sagittal and B) axial showing signi cant improvement after 4 months of therapy with corticosteroids and rituximab treatment (arrow). e degree of enhancement has improved; however, the non enhancing component remains unchanged(arrow head).

IgG4 cells and we relay that to lack of clinical suspicious of the disease at that time.

The IgG4 serum level is usually not a helpful parameter for diagnosing IgG4-related spinal pachymeningitis since it is normal in approximately $80 \%$ of cases as described by Kosakai and $\mathrm{Lu}^{3}$ However, it proved to be a valuable diagnostic addition to our case as the high serum IgG4 level was helpful in making probable diagnosis of IgG4-related spinal pachymeningitis in our patient specially in the absence of an immunohistochemical study.

Methotrexate has shown efficacy in IgG4-related disease symptoms in $<50 \%$ percent of the cases. ${ }^{8}$ Our case was initially treated as seronegative rheumatoid arthritis 3 years after his surgery after which the patient receive methotrexate, which led to symptom improvement, but unfortunately masked and delayed the diagnosis of IgG4-related pachymeningitis for $>10$ years.

Favorable response to glucocorticoids (ranged from $1 \mathrm{mg} / \mathrm{kg}$ and $1000 \mathrm{mg}$ per day) is noticed in described cases of IgG4-related pachymeningitis. Rituximab has been prospectively investigated in treating IgG4-related disease with shown $97 \%$ response rate and case reports describe it is efficacy in neurological involvement of IgG4-related disease. ' The duration of clinical and radiological improvement varies; our patient's numbness improved within 2 days and completely resolved by one week. However, the weakness partially improved by the 4-months follow-up, which could have been due to the extensive involvement of the cervical spine and long duration before treatment initiation.
Lu et $\mathrm{al}^{3}$ used inflammatory markers, such erythrocyte sedimentation rate (ESR) and C-reactive protein (CRP), as markers for monitoring of disease activity in his case, while normal ESR and CRP in our patient did not provide any guidance. Emanuel and $\mathrm{Lu}^{10}$ described the possible significant diagnostic and treatment monitoring role of CSF IgG4 level indices in 2 cases of IgG4-related hypertrophic pachymeningitis. No CSF IgG4 levels were sent to the laboratory for our patient due to lack of suspicion of this disease entity at the time of his lumber puncture; however, we believe that elevated IgG4 levels will support diagnosis and be helpful for treatment follow up for IgG4-related pachymeningitis.

In conclusion, IgG4-related pachymeningitis mainly affects adult males and can mimic rheumatoid arthritis. The presence of slowly progressive limbs weakness associated with an epidural mass should arouse clinical suspicion of this disease. Normal serum IgG4 level should not exclude the disease, but the CSF IgG4 indices have a valuable role in its diagnosis in case a surgical biopsy cannot be carried out. The use of Rituximab and glucocorticoid produced significant clinical and radiological improvement in our patient.

Acknowledgment. The Author would like to extend special thanks to Dr. Ali Alrehaily, rheumatology consultant in the Department of Medicine, Security Forces Hospital, Riyadh, Saudi Arabia for his support and encouragement for writing this study. Also we thank Dr. Prasad Hanagandi, radiologist consultant in the Department of Radiology, King Abdulaziz Medical City, Riyadh, Saudi Arabia for his cooperation in describing the MRI images findings. Also I would like to thank the American Manuscript Editors (www. americanmanuscripteditors.com) for English language editing. 


\section{References}

1. Stone JH, Zen Y, Deshpande V. IgG4-related disease. $N$ Engl J Med 2012; 366: 539-551.

2. AbdelRazek MA, Venna N, Stone JH. IgG4-related disease of the central and peripheral nervous systems. Lancet Neurol 2018; 17: 183-192.

3. Lu Z, Tongxi L, Jie L, Yujuan J, Wei J, Xia L, et al. IgG4-related spinal pachymeningitis. Clin Rheumatol 2016; 35: 1549-1553.

4. Deshpande V, Zen Y, Chan JK, Yi EE, Sato Y, Yoshino T, et al. Consensus statement on the pathology of IgG4-related disease. Mod Pathol 2012; 25: 1181-1192.

5. Masaki Y, Dong L, Kurose N, Kitagawa K, Morikawa Y, Yamamoto M, et al. Proposal for a new clinical entity, IgG4positive multiorgan lymphoproliferative syndrome: analysis of 64 cases of IgG4-related disorders. Ann Rheum Dis 2009; 8: 1310-1315.

6. Farah Z, Mo N. A case of IgG 4 oligoarthritis mimicking psoriatic arthritis. BMJ Case Rep 2018; 2018: bcr-2017222584 .
7. Khosroshahi A, Wallace ZS, Crowe JL, Akamizu T, Azumi $\mathrm{A}$, Carruthers $\mathrm{MN}$, et al. International Consensus Guidance Statement on the Management and Treatment of IgG4Related Disease. Arthritis Rheumatol (Hoboken, NJ) 2015; 67: 1688-1699.

8. Karim AF, Bansie RD, Rombach SM, Paridaens D, Verdijk RM, van Hagen PM, et al. The treatment outcomes in IgG4-related disease. Neth J Med 2018; 76: 275-285.

9. Carruthers MN, Topazian MD, Khosroshahi A, Witzig TE, Wallace ZS, Hart PA, et al. Rituximab for IgG4-related disease: a prospective, open-label trial. Ann Rheum Dis 2015; 74: 1171-1177.

10. Della-Torre E, Passerini G, Furlan R, Roveri L, Chieffo $\mathrm{R}$, Anzalone $\mathrm{N}$, et al. Cerebrospinal fluid analysis in immunoglobulin G4-related hypertrophic pachymeningitis. $J$ Rheumatol 2013; 40: 1927-1929.

\section{Clinical Practice Guidelines}

Clinical Practice Guidelines must include a short abstract. There should be an Introduction section addressing the objective in producing the guideline, what the guideline is about and who will benefit from the guideline. It should describe the population, conditions, health care setting and clinical management/diagnostic test. Authors should adequately describe the methods used to collect and analyze evidence, recommendations and validation. If it is adapted, authors should include the source, how, and why it is adapted? The guidelines should include not more than 50 references, 2-4 illustrations/tables, and an algorithm. 